\title{
Normal Findings on Noninvasive Cardiac Assessment and the Prediction of Heart Failure: The Multi-Ethnic Study of Atherosclerosis (MESA)
}

Stephen T. Broughton, MD'1 , Wesley T. O'Neal, MD, MPH², Mouaz Al-Mallah, MD, MSc ${ }^{3,4}$, David A. Bluemke, MD, PhD ${ }^{5}$, Susan R. Heckbert, MD, $\mathrm{PhD}^{6}$, Joao A. C. Lima, MD $^{7}$, and Elsayed Z. Soliman, MD, MSc, MS ${ }^{8,9}$

${ }^{1}$ Department of Internal Medicine, Wake Forest School of Medicine, Winston-Salem, NC, USA ${ }^{2}$ Deparment of Medicine, Division of Cardiology, Emory University School of Medicine, Atlanta, GA, USA

${ }^{3}$ Division of Cardiovascular Medicine, Henry Ford Hospital, Detroit, MI, USA

${ }^{4}$ Department of Cardiac Imaging, King Abdul Aziz Cardiac Center, Riyadh, Saudi Arabia

${ }^{5}$ Radiology and Imaging Sciences, National Institutes of Health, Bethesda, MD, USA

${ }^{6}$ Department of Epidemiology and Cardiovascular Health Research Unit, University of Washington, Seattle, WA, USA

${ }^{7}$ Department of Medicine, Division of Cardiology, and Department of Radiology, Johns Hopkins University, Baltimore, MD, USA

${ }^{8}$ Department of Internal Medicine, Section on Cardiology, Wake Forest School of Medicine, Winston-Salem, NC, USA

${ }^{9}$ Epidemiological Cardiology Research Center (EPICARE), Department of Epidemiology and Prevention, Wake Forest School of Medicine, Winston-Salem, NC, USA

\section{Abstract}

Background-It is unknown if normal findings on noninvasive cardiac assessment are able to identify individuals who are low risk for developing heart failure (HF).

Methods-We examined if normal findings on the routine electrocardiogram (ECG) and cardiac magnetic resonance imaging (MRI) were able to identify individuals who are low risk for developing $\mathrm{HF}$ in 4,986 (mean age $=62 \pm 10$ years; $52 \%$ women; $39 \%$ White; $13 \%$ Chinese-

American; 26\% Black; 22\% Hispanic) participants from the Multi-Ethnic Study of Atherosclerosis who were free of clinically apparent HF at baseline. A normal ECG was defined as the absence of

Corresponding Author: Wesley T. O'Neal, MD, MPH, Department of Medicine, Division of Cardiology, Emory University School of Medicine, 101 Woodruff Circle, Woodruff Memorial Building Atlanta, GA 30322, wesley.oneal@emory.edu.

Disclosures: The authors report no relationships that could be construed as a conflict of interest.

Publisher's Disclaimer: This is a PDF file of an unedited manuscript that has been accepted for publication. As a service to our customers we are providing this early version of the manuscript. The manuscript will undergo copyediting, typesetting, and review of the resulting proof before it is published in its final citable form. Please note that during the production process errors may be discovered which could affect the content, and all legal disclaimers that apply to the journal pertain. 
major abnormalities by Minnesota Code Classification, and a normal MRI was defined as absence of structural abnormalities and systolic dysfunction.

Results-There were 3,988 (80\%) participants with normal findings at baseline on both ECG and MRI, 894 (18\%) who had either a normal ECG or normal MRI, and 104 (2\%) who had abnormal findings on ECG and MRI. Over a median follow-up of 12.2 years, 177 (3.6\%) HF events occurred. Normal ECG $(\mathrm{HR}=0.41,95 \% \mathrm{CI}=0.29,0.56)$ and $\mathrm{MRI}(\mathrm{HR}=0.32,95 \% \mathrm{CI}=0.23$, 0.45 ) were each associated with lower risk of HF compared with abnormal, and their combination was associated with a lower $\mathrm{HF}$ risk $(\mathrm{HR}=0.13,95 \% \mathrm{CI}=0.08,0.21)$ than either in isolation.

Conclusion-Normal findings on noninvasive cardiac assessment identify individuals in whom the risk of HF is low. Further studies are needed to explore the utility of this low-risk profile in HF prevention strategies.

\section{Keywords}

heart failure; noninvasive cardiac assessment; epidemiology

\section{INTRODUCTION}

Despite improvements in medical therapies, heart failure (HF) continues to place a significant burden on the United States health care system. An estimated 5.7 million Americans have HF, and the prevalence is expected to increase by $46 \%$ between 2012 and $2030[1,2]$. Therefore, the accurate prediction of future HF events is of paramount importance to appropriately target preventive therapies and deliver necessary medical care.

Numerous risk factors for HF have been identified (e.g., diabetes, hypertension, dyslipidemia) [3-5]. In this framework of risk factor identification, the severity of biological and structural abnormalities are clearly associated with an increased risk of HF. However, several reports have shown that much information is obtained from normal findings, as those with favorable risk factor profiles have a decreased risk for cardiovascular disease-related mortality [6,7]. Additionally, a favorable risk factor profile reclassifies persons to lower risk categories [8], implicating a role for normal findings to influence the decision to initiate or, more importantly, reduce certain risk factor modification strategies (e.g., lipid-lowering therapies).

The resting 12-lead electrocardiogram (ECG) is the most widely used tool for cardiovascular risk assessment. Several reports have demonstrated that ECG abnormalities in asymptomatic persons are predictive of incident HF [9-12]. Similarly, abnormalities of left ventricular structure and function on cardiac magnetic resonance imaging (MRI) are predictive of HF development $[13,14]$. However, whether the presence of normal findings on routine ECG and cardiac MRI can identify individuals at a reduced risk for HF is currently unknown. Therefore, the purpose of this analysis was to examine the association of normal findings on the routine ECG and cardiac MRI with HF development in the Multi-Ethnic Study of Atherosclerosis (MESA). 


\section{METHODS}

\section{Study Population}

Details of MESA have been reported previously [15]. Briefly, between July 2000 and September 2002, a total of 6,814 persons were recruited at 6 field centers in the United States (Baltimore, Maryland; Chicago, Illinois; Forsyth County, North Carolina; Los Angeles, California; New York, New York; and St. Paul, Minnesota). Participants were required to be between 45 and 84 years of age and to have no clinical cardiovascular disease. All participants provided informed consent and the study protocol was approved by the Institutional Review Boards at each participating institution. Participants were excluded if they did not undergo baseline ECG or cardiac MRI measurements. Additionally, we excluded participants without baseline covariates or follow-up data.

\section{Baseline Characteristics}

Participant characteristics were collected during the initial MESA visit. Age, sex, and race/ ethnicity were self-reported. Smoking was defined as ever (e.g., current or former) versus never smoker. Blood samples were obtained after a 12-hour fast and measurements of total cholesterol, high-density lipoprotein cholesterol, and plasma glucose were used. Diabetes was defined as fasting glucose values $\geq 126 \mathrm{mg} / \mathrm{dL}$ or a history of diabetes medication use. Blood pressure was measured 3 times after 5 minutes in the seated position, and the mean of the last 2 values was used. The use of aspirin, lipid-lowering therapies, and antihypertensive medications was self-reported. Body mass index was computed as the weight in kilograms divided by the square of the height in meters.

\section{Electrocardiogram (ECG)}

In MESA, 12-lead digital ECGs were obtained by trained technicians using GE MAC 1200 electrocardiographs using standardized procedures. ECGs were transmitted electronically to the MESA ECG Reading Center located at the Epidemiological Cardiology Research Center (Wake Forest School of Medicine, Winston-Salem, NC). All ECGs were automatically processed, after visual inspection for technical errors and quality, using the 2001 version of the GE Marquette 12-SL program (GE, Milwaukee, Wisconsin, USA). Normal ECGs were defined as the absence of significant (e.g., major) abnormalities using the Minnesota Code classification system [16]. This included the absence of major ventricular conduction defects (complete left or right bundle branch block, major ventricular conduction delay with QRS $\geq 120 \mathrm{~ms}$ ), major Q wave abnormalities, isolated major ST/T wave abnormalities, left ventricular hypertrophy, advanced atrioventricular block, electronic pacemaker, atrial fibrillation/flutter, and others.

\section{Cardiac MRI}

Participants in MESA underwent cardiac MRI assessment during the baseline study visit using standard procedures. The MESA cardiac MRI protocol, image analysis, and inter- and intra-reader reproducibility have been previously reported [13]. A normal cardiac MRI was defined by the absence of left ventricular enlargement (left ventricular end-diastolic mass ( $\mathrm{g}$ ) 
normalized to body surface area $\left(\mathrm{m}^{2}\right)$ within sex-specific limits: men: $<106.2 \mathrm{~g} / \mathrm{m}^{2}$; women: $<84.6 \mathrm{~g} / \mathrm{m}^{2}$ ) and systolic dysfunction (ejection fraction $<55 \%$ ) [17].

\section{Heart Failure}

The ascertainment of incident HF events has been previously described [18]. Participants were followed for incident cardiovascular events from baseline through December 31, 2013. At intervals of 9-12 months, a telephone interviewer contacted each participant to inquire about all interim hospital admissions, cardiovascular outpatient diagnoses, procedures, and deaths. Additionally, MESA occasionally identified medical encounters through cohort clinic visits, participant call-ins, medical record abstractions, or obituaries. Next of kin interviews for out of hospital cardiovascular deaths also were used. The outcome of interest for this analysis was the composite of probable and definite HF events. Definite or probable $\mathrm{HF}$ required symptoms, such as shortness of breath or edema, as asymptomatic disease is not a MESA endpoint. In addition to symptoms, probable HF required a physician diagnosis and also for the patient to be receiving medical treatment for HF. Definite HF required one or more other criteria, such as pulmonary edema/congestion by chest X-ray; dilated ventricle or poor left ventricular function by echocardiography or ventriculography; or evidence of left ventricular diastolic dysfunction [19]. For this analysis, systolic and diastolic HF events were grouped together.

\section{Statistics}

Participants were grouped into the following 3 categories based on their baseline cardiac assessment: 1) abnormal ECG + abnormal MRI (referent); 2) normal ECG or normal MRI; 3) normal ECG + normal MRI. Descriptive statistics were compared between the 3 categories. Categorical data were compared using the chi-square method, and the KruskalWallis procedure was used for continuous data. Kaplan-Meier estimates were computed for the cumulative incidence of HF events during the study period. The 1-, 5-, and 10-year cumulative incidence estimates were tabulated. Follow-up time was defined as the time from the initial study visit until one of the following: HF development, loss to follow-up, death, or end of the study period (December 31, 2013). Cox regression was used to compute hazard ratios (HR) and 95\% confidence intervals (CI) for the association of the above categories with HF. Multivariable models included the following covariates: Model 1 included age, sex, and race; Model 2 included Model 1 covariates with the addition of systolic blood pressure, diabetes, body mass index, total cholesterol, high-density lipoprotein cholesterol, smoking, antihypertensive medications, lipid-lowering therapies, and aspirin. Statistical significance was defined as $\mathrm{p}<0.05$. SAS Version 9.4 (Cary, NC) was used for all analyses.

\section{RESULTS}

A total of 4,986 (mean age $=62 \pm 10$ years; $52 \%$ women; 39\% White; $13 \%$ Chinese-

American; 26\% Black; 22\% Hispanic) participants were included in the final analysis. Of these, 3,988 (80\%) had normal ECG + normal MRI, 894 (18\%) had either a normal ECG or normal MRI, and 104 (2\%) had an abnormal ECG + abnormal MRI. Baseline characteristics stratified by these groups are summarized in Table 1. As shown, participants with abnormal ECG + abnormal MRI were more likely to be older, male, to have diabetes and higher values 
of systolic blood pressure and LV mass, but lower high-density lipoprotein cholesterol, compared with those with normal ECG or normal MRI.

Over a median follow-up of 12.2 years $\left(25^{\text {th }}-75^{\text {th }}\right.$ percentiles $\left.=11.6,12.8\right)$, a total of 177 (3.6\%) HF events were detected. The 1-, 5-, and 10-year cumulative incidence estimates of HF events in each category are tabulated in Table 2. As shown, for all time periods, the cumulative incidence of HF was lower for those with normal ECG + normal MRI findings compared with other categories. The cumulative incidence of HF for each category is depicted graphically in Figure 1.

The risk estimates for HF across categories of normal ECGs and/or normal MRI findings are shown in Table 3. In isolation, the normal ECG $(\mathrm{HR}=0.41,95 \% \mathrm{CI}=0.29,0.56)$ and normal MRI $(\mathrm{HR}=0.32,95 \% \mathrm{CI}=0.23,0.45)$ were associated with a reduced risk of HF. The risk for $\mathrm{HF}$ was lowest for those with normal ECG + normal MRI (HR=0.13, 95\% CI $=0.08,0.21)$ (Table 3).

\section{DISCUSSION}

In this analysis from MESA, the absence of significant abnormalities on the 12-lead ECG, and the absence of structural abnormalities and systolic dysfunction by cardiac MRI, were associated with a lower risk for HF development compared with those who had abnormal findings on these measurements. Overall, the findings of this analysis suggest that persons with normal noninvasive cardiac profiles represent a group in whom the risk of future HF is unlikely, and this profile possibly is able influence the decision to implement certain risk factor modification strategies with aims to prevent HF.

Prior reports have focused on the association of abnormalities on the ECG and cardiac MRI with incident HF events. Data from the Women's Health Initiative [9], Atherosclerosis Risk In Communities study [10], MESA [11], and Health, Aging, and Body Composition study [12], have shown that ECG abnormalities predict incident HF. Similar findings have been reported for cardiac MRI measures, such as enlarged left ventricular mass and diameter [13, 14]. The results from the studies mentioned above clearly indicate that abnormalities detected on routine ECG and cardiac MRI assessment are associated with an increased risk of incident HF events among individuals without baseline cardiovascular disease.

In the present study, we have demonstrated that important prognostic information regarding HF development is obtained with normal findings on the routine ECG and cardiac MRI. The protective benefit for HF development was independent of well-known risk factors.

Presumably, participants with these normal findings were less susceptible to the deleterious effects of common risk factors through favorable genetics, healthful behaviors, and other unmeasured factors. However, further research is needed to better characterize this population and to determine which factors (e.g., genetics) most positively influence the maintenance of normal findings on the routine ECG and cardiac MRI. Nonetheless, we have demonstrated that important prognostic information is obtained on normal findings of noninvasive cardiac assessment. Furthermore, providers are likely to encounter normal findings on noninvasive cardiac tools [20], and these data allow providers to inform patients 
of their low risk if this profile is present, and to encourage healthful behaviors that are known to reduce future HF events [21].

By 2030, the prevalence of HF is projected to increase by $23 \%$ with more than $26 \%$ of cases expected to occur in persons $>80$ years of age [1]. This coincides with an increase in the projected total medical costs related to HF to nearly $\$ 53.1$ billion [1]. Due to the rather large burden that will be placed on the health care system to treat HF and finance the care provided, an in-depth understanding of risk factors is of paramount importance for the development of interventions aimed at prevention. The findings of this analysis suggest that persons who have normal findings on the routine ECG, and the absence of structural abnormalities and systolic dysfunction on cardiac MRI, are less likely to develop HF, despite the presence of well-known risk factors. This possibly has important implications regarding the clinical decision to initiate certain risk factor modification strategies, as these therapies potentially are unnecessary in the right clinical setting (e.g., normal ECG and normal structural profile). For example, the identification of this normal cardiac profile on noninvasive cardiac assessment possibly is beneficial when contemplating invasive strategies to reduce the risk of future HF events in persons who are intermediate risk. However, further research is needed to determine the underlying mechanisms that reduce HF risk in this population before changes in clinical practice are recommended.

The current study should be interpreted in the context of several limitations. Incident HF cases were identified by subsequent study visits, follow-up phone calls, and the examination of hospitalization data including International Classification of Diseases codes. Despite these efforts to account for all HF events, some cases possibly were missed. Although we classified ECG abnormalities using the Minnesota Code, the most widely used classification system in population studies [16], it is possible that our results vary with different definitions. Similarly, normal cardiac MRI findings were defined by the absence of left ventricular enlargement and systolic dysfunction. Despite the detailed information that is obtained during cardiac MRI, the definition used in this study is easily interpreted by clinicians across multiple specialties. Also, the definition used was highly protective of future $\mathrm{HF}$ events, indicating that the criteria used were adequate to describe a normal cardiac MRI profile for HF risk assessment. Finally, several potential confounders were included in our multivariable models but similar to other epidemiological studies we acknowledge that residual confounding remains a possibility.

In conclusion, we have shown that normal findings on the routine ECG and cardiac MRI identify individuals in whom the risk of HF is low. This provides clinicians with valuable information regarding HF risk assessment in the face of normal findings on noninvasive cardiac assessment.

\section{Acknowledgments}

Funding: This research was supported by contracts N01-HC-95159, N01-HC-95160, N01-HC-95161, N01HC-95162, N01-HC-95163, N01-HC-95164, N01-HC-95165, N01-HC-95166, N01-HC-95167, N01-HC-95168 and N01-HC-95169 from the National Heart, Lung, and Blood Institute and by grants UL1-TR-000040 and UL1TR-001079 from NCRR. WTO is supported by the National Heart, Lung, And Blood Institute of the National Institutes of Health under Award Number F32-HL-134290. The content is solely the responsibility of the authors and does not necessarily represent the official views of the National Institutes of Health. 
The authors thank the other investigators, the staff, and the participants of the MESA study for their valuable contributions. A full list of participating MESA investigators and institutions can be found at http://www.mesanhlbi.org.

\section{References}

1. Heidenreich PA, Albert NM, Allen LA, Bluemke DA, Butler J, Fonarow GC, et al. Forecasting the impact of heart failure in the United States: a policy statement from the American Heart Association. Circ Heart Fail. 2013; 6:606-19. [PubMed: 23616602]

2. Mozaffarian D, Benjamin EJ, Go AS, Arnett DK, Blaha MJ, Cushman M, et al. Heart disease and stroke statistics--2015 update: a report from the American Heart Association. Circulation. 2015; 131:e29-e322. [PubMed: 25520374]

3. Kannel WB, D’Agostino RB, Silbershatz H, Belanger AJ, Wilson PW, Levy D. Profile for estimating risk of heart failure. Arch Intern Med. 1999; 159:1197-204. [PubMed: 10371227]

4. Gottdiener JS, Arnold AM, Aurigemma GP, Polak JF, Tracy RP, Kitzman DW, et al. Predictors of congestive heart failure in the elderly: the Cardiovascular Health Study. J Am Coll Cardiol. 2000; 35:1628-37. [PubMed: 10807470]

5. Avery CL, Loehr LR, Baggett C, Chang PP, Kucharska-Newton AM, Matsushita K, et al. The population burden of heart failure attributable to modifiable risk factors: the ARIC (Atherosclerosis Risk in Communities) study. J Am Coll Cardiol. 2012; 60:1640-6. [PubMed: 23021327]

6. Stamler J, Stamler R, Neaton JD, Wentworth D, Daviglus ML, Garside D, et al. Low risk-factor profile and long-term cardiovascular and noncardiovascular mortality and life expectancy: findings for 5 large cohorts of young adult and middle-aged men and women. JAMA. 1999; 282:2012-8. [PubMed: 10591383]

7. Daviglus ML, Stamler J, Pirzada A, Yan LL, Garside DB, Liu K, et al. Favorable cardiovascular risk profile in young women and long-term risk of cardiovascular and all-cause mortality. JAMA. 2004; 292:1588-92. [PubMed: 15467061]

8. Blaha MJ, Cainzos-Achirica M, Greenland P, McEvoy JW, Blankstein R, Budoff MJ, et al. Role of Coronary Artery Calcium Score of Zero and Other Negative Risk Markers for Cardiovascular Disease: The Multi-Ethnic Study Of Atherosclerosis (MESA). Circulation. 2016

9. Rautaharju PM, Kooperberg C, Larson JC, LaCroix A. Electrocardiographic predictors of incident congestive heart failure and all-cause mortality in postmenopausal women: the Women's Health Initiative. Circulation. 2006; 113:481-9. [PubMed: 16449727]

10. Rautaharju PM, Prineas RJ, Wood J, Zhang ZM, Crow R, Heiss G. Electrocardiographic predictors of new-onset heart failure in men and in women free of coronary heart disease (from the Atherosclerosis in Communities [ARIC] Study). Am J Cardiol. 2007; 100:1437-41. [PubMed: 17950804]

11. Ilkhanoff L, Liu K, Ning H, Nazarian S, Bluemke DA, Soliman EZ, et al. Association of QRS duration with left ventricular structure and function and risk of heart failure in middle-aged and older adults: the Multi-Ethnic Study of Atherosclerosis (MESA). Eur J Heart Fail. 2012; 14:128592. [PubMed: 22791081]

12. Gencer B, Butler J, Bauer DC, Auer R, Kalogeropoulos A, Marques-Vidal P, et al. Association of electrocardiogram abnormalities and incident heart failure events. Am Heart J. 2014; 167:869-75. e3. [PubMed: 24890537]

13. Bluemke DA, Kronmal RA, Lima JA, Liu K, Olson J, Burke GL, et al. The relationship of left ventricular mass and geometry to incident cardiovascular events: the MESA (Multi-Ethnic Study of Atherosclerosis) study. J Am Coll Cardiol. 2008; 52:2148-55. [PubMed: 19095132]

14. Yeboah J, Bluemke DA, Hundley WG, Rodriguez CJ, Lima JA, Herrington DM. Left ventricular dilation and incident congestive heart failure in asymptomatic adults without cardiovascular disease: multi-ethnic study of atherosclerosis (MESA). J Card Fail. 2014; 20:905-11. [PubMed: 25225112]

15. Bild DE, Bluemke DA, Burke GL, Detrano R, Diez Roux AV, Folsom AR, et al. Multi-ethnic study of atherosclerosis: objectives and design. Am J Epidemiol. 2002; 156:871-81. [PubMed: 12397006] 
16. Prineas, RJ., Crow, RS., Zhang, ZM. The Minnesota code manual of electrocardiographic findings: standards and procedures for measurement and classification. 2. London: Springer; 2010.

17. Brumback LC, Kronmal R, Heckbert SR, Ni H, Hundley WG, Lima JA, et al. Body size adjustments for left ventricular mass by cardiovascular magnetic resonance and their impact on left ventricular hypertrophy classification. Int J Cardiovasc Imaging. 2010; 26:459-68. [PubMed: 20107905]

18. Bahrami H, Kronmal R, Bluemke DA, Olson J, Shea S, Liu K, et al. Differences in the incidence of congestive heart failure by ethnicity: the multi-ethnic study of atherosclerosis. Arch Intern Med. 2008; 168:2138-45. [PubMed: 18955644]

19. Nagueh SF, Smiseth OA, Appleton CP, Byrd BF 3rd, Dokainish H, Edvardsen T, et al. Recommendations for the Evaluation of Left Ventricular Diastolic Function by Echocardiography: An Update from the American Society of Echocardiography and the European Association of Cardiovascular Imaging. J Am Soc Echocardiogr. 2016; 29:277-314. [PubMed: 27037982]

20. De Bacquer D, De Backer G, Kornitzer M. Prevalences of ECG findings in large population based samples of men and women. Heart. 2000; 84:625-33. [PubMed: 11083741]

21. Folsom AR, Shah AM, Lutsey PL, Roetker NS, Alonso A, Avery CL, et al. American Heart Association's Life's Simple 7: Avoiding Heart Failure and Preserving Cardiac Structure and Function. Am J Med. 2015; 128:970-6. e2. [PubMed: 25908393] 

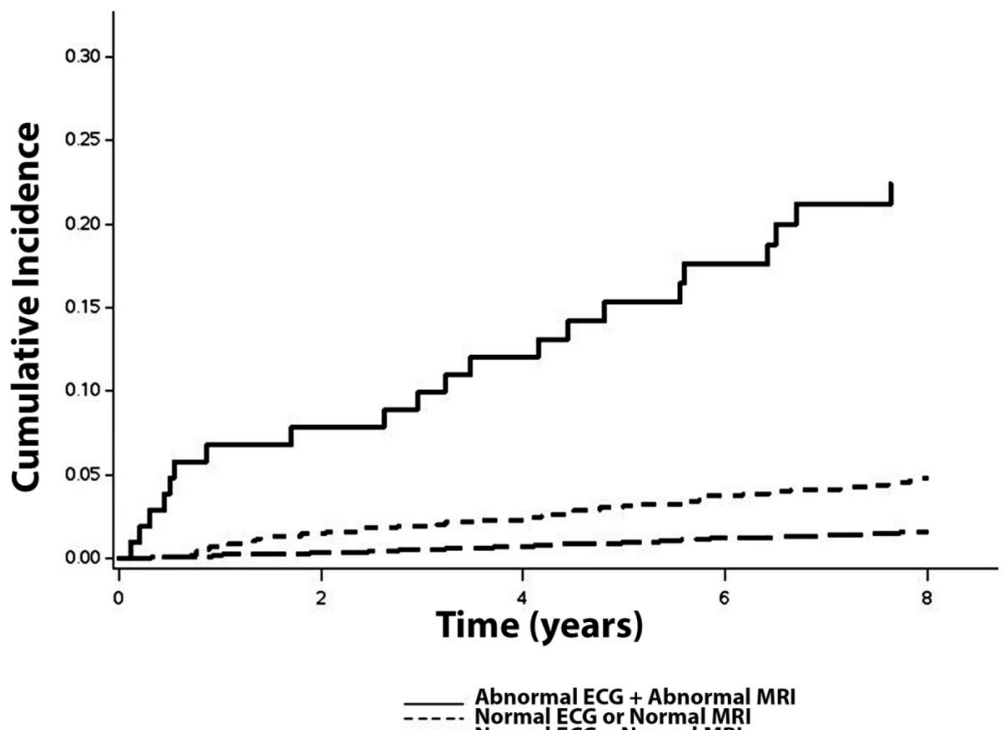

---- Normal ECG or Normal MR

Figure 1. Cumulative Incidence of Heart Failure ${ }^{*}$

* Cumulative incidence curves are statistically different (log-rank p<0.001). 


\section{Table 1}

Baseline Characteristics $(\mathrm{N}=4,986)$

\begin{tabular}{|c|c|c|c|c|}
\hline Characteristic & $\begin{array}{c}\text { Abnormal ECG }+ \\
\text { Abnormal MRI }(n=104)\end{array}$ & $\begin{array}{c}\text { Normal ECG or } \\
\text { Normal MRI }(n=894)\end{array}$ & $\begin{array}{c}\text { Normal ECG + Normal } \\
\text { MRI }(\mathbf{n}=\mathbf{3 , 9 8 8})\end{array}$ & P-value \\
\hline Age, mean $\pm \mathrm{SD}$, years & $66 \pm 10$ & $63 \pm 10$ & $61 \pm 10$ & $<0.001$ \\
\hline Male (\%) & $69(66)$ & $536(60)$ & $1,769(44)$ & $<0.001$ \\
\hline Race & & & & $<0.001$ \\
\hline White $(\%)$ & $42(40)$ & $366(41)$ & $1,539(39)$ & \\
\hline Chinese-American (\%) & $3(3.0)$ & $78(9.0)$ & $570(14)$ & \\
\hline Black $(\%)$ & $40(39)$ & $267(30)$ & $973(24)$ & \\
\hline Hispanic (\%) & $19(18)$ & $183(20)$ & $906(23)$ & \\
\hline Ever smoker $(\%)$ & $65(63)$ & $464(52)$ & $1,886(47)$ & $<0.001$ \\
\hline Diabetes $(\%)$ & $25(24)$ & $143(16)$ & $468(12)$ & $<0.001$ \\
\hline Systolic blood pressure, mean $\pm \mathrm{SD}, \mathrm{mm} \mathrm{Hg}$ & $140 \pm 27$ & $128 \pm 22$ & $124 \pm 21$ & $<0.001$ \\
\hline Body mass index, mean $\pm \mathrm{SD}, \mathrm{kg} / \mathrm{m}^{2}$ & $28 \pm 4.6$ & $28 \pm 4.7$ & $27 \pm 5.0$ & 0.11 \\
\hline $\mathrm{HDL}$ cholesterol, mean $\pm \mathrm{SD}, \mathrm{mg} / \mathrm{dL}$ & $48 \pm 15$ & $50 \pm 15$ & $52 \pm 15$ & $<0.001$ \\
\hline Total cholesterol, mean $\pm \mathrm{SD}, \mathrm{mg} / \mathrm{dL}$ & $191 \pm 41$ & $193 \pm 36$ & $195 \pm 35$ & 0.21 \\
\hline $\mathrm{LV}$ mass/BSA, mean $\pm \mathrm{SD}, \mathrm{g} / \mathrm{m}^{2}$ & $84 \pm 23$ & $69 \pm 13$ & $63 \pm 10$ & $<0.001$ \\
\hline Antihypertensive medications (\%) & $53(51)$ & $358(40)$ & $1,349(34)$ & $<0.001$ \\
\hline Lipid-lowering medications (\%) & $19(18)$ & $159(18)$ & $615(15)$ & 0.17 \\
\hline Aspirin use (\%) & $34(33)$ & $227(25)$ & $895(22)$ & 0.011 \\
\hline
\end{tabular}

* Statistical significance for continuous data was tested using the Kruskal-Wallis test and categorical data was tested using the chi-square method.

BSA=body surface area; $\mathrm{ECG}=$ electrocardiogram; $\mathrm{HDL}=$ high-density lipoprotein; $\mathrm{LV}=$ left ventricle; $\mathrm{MRI}=$ magnetic resonance imaging; $\mathrm{SD}=$ standard deviation. 
Table 2

1-, 5-, and 10-year Cumulative Incidence of Heart Failure

\begin{tabular}{lccc}
\hline Category & 1-year (\%) & 5-year (\%) & 10-year (\%) \\
\hline Abnormal ECG + Abnormal MRI & 6.8 & 15 & 25 \\
Normal ECG or Normal MRI & 0.7 & 3.1 & 5.6 \\
Normal ECG + Normal MRI & 0.2 & 0.9 & 2.2 \\
\hline
\end{tabular}

ECG=electrocardiogram; MRI=magnetic resonance imaging. 


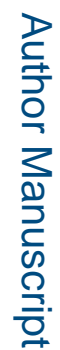

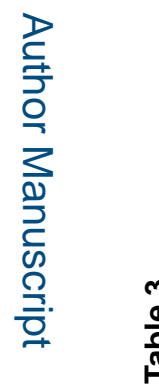

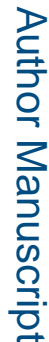

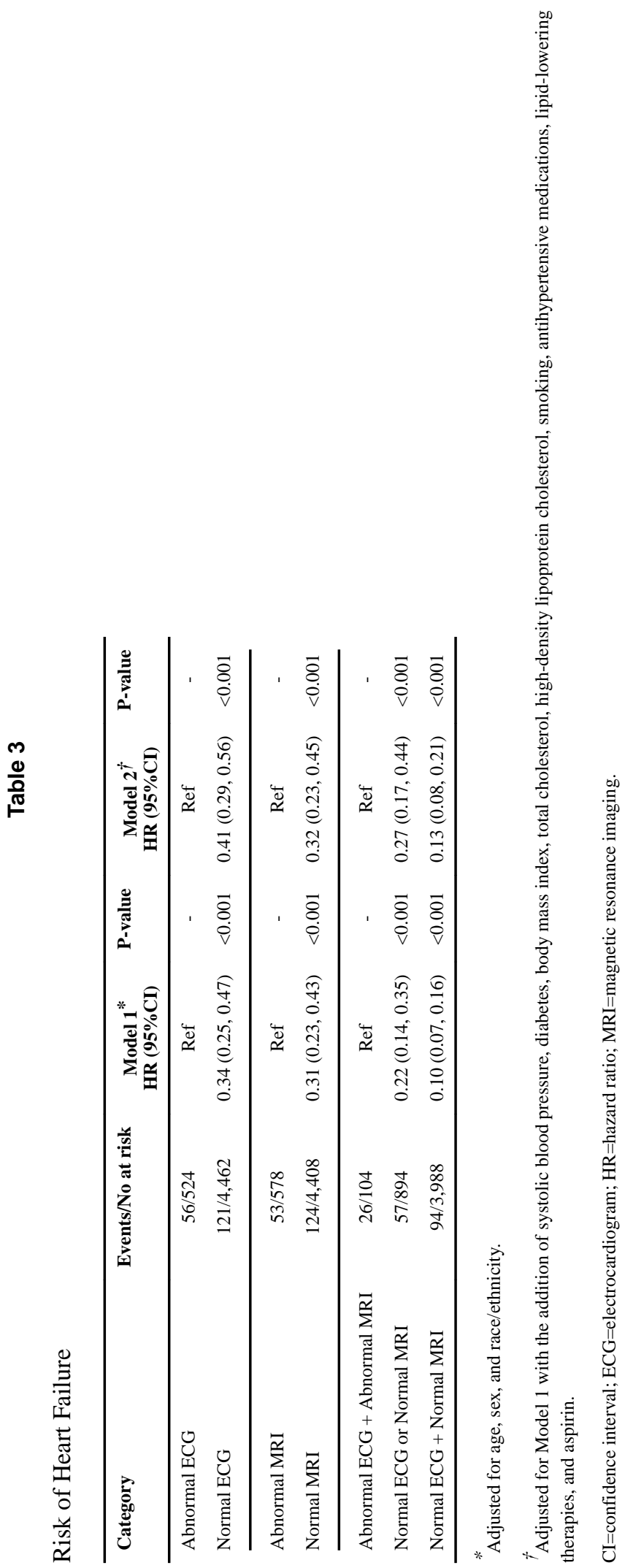

